\title{
Anxiety and Depression among Exact and Natural Science College Students of BUAP-México under COVID-19 Lockdown
}

\author{
Alan Carrasco-Carballo1,2, Luis D. Luna-Centeno ${ }^{3}$, Alberto Rojas-Morales ${ }^{1,2}$, Victorino Alatriste1, \\ Isabel Martínez1 ${ }^{1}$ Liliana Martínez ${ }^{1}$, Daniel Limón ${ }^{1}$, Félix Luna ${ }^{*}$
}

\footnotetext{
${ }^{1}$ Departamento de Farmacia, Facultad de Ciencias Químicas, Benemérita Universidad Autónoma de Puebla, Puebla, México ${ }^{2}$ Laboratorio de Elucidación y Síntesis en Química Orgánica, Benemérita Universidad Autónoma de Puebla, Puebla, México ${ }^{3}$ Keck School of Medicine, University of Southern California Health Sciences Campus, Los Angeles, USA Email: ^felix.luna@correo.buap.mx
}

How to cite this paper: Carrasco-Carballo, A., Luna-Centeno, L. D., Rojas-Morales, A., Alatriste, V., Martínez, I., Martínez, L., Limón, D., \& Luna, F. (2021). Anxiety and Depression among Exact and Natural Science College Students of BUAP-México under COVID-19 Lockdown. Open Journal of Depression, 10, 103-120.

https://doi.org/10.4236/ojd.2021.103007

Received: May 30, 2021

Accepted: June 29, 2021

Published: July 2, 2021

Copyright $\odot 2021$ by author(s) and Scientific Research Publishing Inc. This work is licensed under the Creative Commons Attribution International License (CC BY 4.0).

http://creativecommons.org/licenses/by/4.0/

\begin{abstract}
The aim of this study was to investigate the prevalence of anxiety and depression among a population of exact and natural science university students from Benemérita Universidad Autónoma de Puebla (BUAP)-México under COVID19 lockdown. Furthermore, we explored influencing factors pertaining to the online learning environment at home. A total of 502 college students; 192 men $(38.2 \%)$ and 310 women (61.8\%) participated in this cross-sectional web-based survey. A Goldberg Anxiety and Depression Scale (GADS) standardized e-questionnaire was generated using Google Forms, and the link was shared through email. The data collection process was conducted during voluntary COVID-19 lockdown during the second university semester (October-November, 2020) and before the final exams period. The data recovered was analyzed in three consecutive levels, including univariate, bivariate, and multivariate analysis. The college students experienced high levels of anxiety and depression. The sampled population of men and women was $75.5 \%$ and 92.3\% respectively measured positive for anxiety, whereas depression was measured at $63.5 \%$ and $78.4 \%$ respectively. Factors influencing at-home elearning such as internet connection quality, internet cost, status of owning or sharing a PC, inhabitants per household and length of academic program completed were correlated positively with high prevalence $(>60 \%)$ of anxiety and depression among students. Based on the reported results, we suggest that both the university authorities and government could work together to address these high levels of anxiety and depression to reduce their impact among university students with the ultimate goal of achieving optimal learning during lockdown conditions.
\end{abstract}




\section{Keywords}

COVID-19 Lockdown, College Student, Anxiety, Depression, E-Learning

Environment at Home

\section{Introduction}

Since coronavirus disease 2019 (COVID-19) emerged, and after its declaration as a global pandemic, all governments around the world have taken severe public health actions to contain the epidemic and to reduce mortality. In Mexico, lockdown due to the COVID-19 health emergency started on March 30, 2020 (SECGOB ACUERDO-a, 2020), and as in many other countries, this choice was influenced in hopes of reducing the use of the healthcare system and restricting viral dissemination. The government, in harmonization with the Mexican Ministry of Health implemented a series of preventions, actions and infection control strategies, including restriction of mass-gathering events, social healthy distance, interruption of "nonessential activities", transition to the use of the home office in all economic sectors, and the recommendation of home confinement for the general population (SECGOB, ACUERDO-b, 2020). In this context, all academic institutions were required to discontinue face-to-face teaching practices.

So far, many studies have shown the impact that COVID-19 lockdown can have and its effects on people's well-being, due to its ability to produce a fullscale mental health crisis (Fiorillo \& Gorwood, 2020; Zhou et al., 2020). In a global study sampling populations from the USA, UK, Pakistan, and Canada, among others, $50.9 \%$ of participants had signs of anxiety, $57.4 \%$ had signs of stress and $58.6 \%$ of participants showed indications of depression (Shah et al., 2021). The COVID-19 pandemic has produced a notable emotional impact on medical workers and college students with important symptoms of stress, anxiety, and depression (Kang et al., 2020; Rehman et al., 2020; Xiong et al., 2020). Additionally, considering the usual high incidence of emotional disorders among Mexican university students (González-Benítez et al., 2020), it can be expected that COVID-19 confinement caused a notable impact on this social group (Kaparounaki et al., 2020; Odriozola-González et al., 2020). Also, it has been reported that undergraduate students had unsatisfactory learning associated with anxiety and depression relating to the COVID-19 lockdown (Rodríguez-Hidalgo et al., 2020). As well, data from college students have shown an increase in worries not only for their education, but also for their well-being, and that of their families as a result of their return home due to suspended in-person academic training (Zhai \& Du, 2020).

Because of the health emergency, higher education institutions have been forced to employ substitute methods of education (Almaiah et al., 2020). Online learning platforms have been put into use to create a virtual classroom in which 
the student and the teacher can connect and realize the learning process. Platforms such as Teams, Blackboard, Moodle, and Google Meet, among others, have been used to deliver curricular content to students, where students have been challenged to adjust to new methods of educational instruction (Nimavat et al., 2021). Although several higher educational institutions have developed online and virtual learning educational programs, these instructional methods have not been extensively validated. Consequently, it is important to show their implications on aspects such as well-being and mental health among the students (Xiong et al., 2020). During confinement, social isolation and reduced physical activity can intensify feelings of insignificance, conditions that may exacerbate mental health problems (Ramos-Morcillo et al., 2020). Furthermore, financial barriers can also impede students' access to technologies that could prevent the deteriorating effects of online learning on important aspects of health, such as irritability, sleep quality, and even insomnia (Khan et al., 2020; Marelli et al., 2020; Solomou \& Constantinidou, 2020). These effects have been shown to have a higher impact on students from lower socioeconomic levels (Rudenstine et al., 2021). Additionally, the emerging literature is beginning to reveal differences between gender and age. Young adults (18 - 24 years old) were more affected compared to other age groups, as well as women being more affected than men (Padrón et al., 2021). Women and younger people show higher levels of depression, anxiety, stress, and fear of COVID-19 (Huang \& Zhao, 2020; Sandín et al., 2020). However, most of these studies were carried out in samples of health workers (Pappa et al., 2020), and much less is known about young people. Undergraduate students have been observed to be more fearful of COVID-19 than graduate students (Reznik et al., 2020). Also, according to some studies, the symptoms of anxiety and depression among these students are increasing due to social distancing induced by lockdown measures (Mazza et al., 2020; Santini et al., 2020).

In Latin America scarcely any studies have been carried out on college students (Rodríguez-Hidalgo et al., 2020). In the current pandemic crisis, studying the causes of anxiety and depression in vulnerable contexts can be of great strategic value to help alleviate these illnesses now, and help prevent them in the future. Before this study, the general Mexican population was placed in confinement for an extended period (eight months), consequently quickly changing the lifestyle of the population, and causing a significant increase of psychological distress and symptoms of mental illness (Cortés-Álvarez et al., 2020; GonzálezRamírez et al., 2020). Mexican university students are being tested in the face of the COVID-19 lockdown, which creates a challenge to their emotional stability and their academic training. However, no research has been done previously that examines Mexican college students with strictly exclusive e-learning during the times of COVID-19 lockdown. The aim of the present study was to evaluate the psychological impact of COVID-19 lockdown on two specific mental symptoms; anxiety and depression, and to evaluate the online home learning environment among BUAP-Mexico university students. 


\section{Methods}

\subsection{Study Design and Participants}

This was a quantitative cross-sectional research design, where the GADS electronic survey was sent to quarantine undergraduate university students via email. The study's significant sample included 502 students from the exact and natural sciences of the BUAP-México. They were included in the study based on the inclusion criteria that they have remained in voluntary home lockdown and have been participating in exclusively online academic learning activities within their respective curricula.

The estimated total sample was 15,000 students and the minimum sample size was calculated with Software Minitab 18 using variance and fixed standard deviation resulting in a minimum of 447 students with $98 \%$ confidence, standard deviation of 0.2 and a population proportion of 0.8 . The confidence interval was calculated with the $\mathrm{Z}$ descriptor of the sample allowing a maximum error of $5 \%$. The study population consisted of an unintentional sample of mathematical, physical, electronic, computer, chemistry, biochemistry, biology, and biotechnology academic programs from the BUAP-México. A total of 502 valid answers were obtained (98\%), from $61.7 \%$ women and $38.3 \%$ men, with ages ranging between 19 - 24 years old. As for the selection criteria, we included undergraduate university students active in online learning. The students were informed of the aims, protocol, and implications of participation in the study, and their consent was obtained. There were no exclusion criteria, other than failure to fully complete the questionnaire.

\subsection{Instruments}

GADS is a tool widely used in clinical research and healthcare practice (Goldberg et al., 1988; Varo et al., 2006). Briefly, this instrument has two subscales with 9 binary (yes/no) items. The first subscale for anxiety, "Have you had difficulty relaxing?" (questions 1 to 9); and the second subscale for depression, "Have you felt low energy?" (questions 10 to 18) were used. The initial questions of each subscale $1-4$ and 10 - 13 respectively are conditioning questions. At least two affirmative answers are required for questions $1-4$ to discontinue the subscale. For the second subscale, one positive answer is needed from questions 10 - 13 to continue answering the subscale. The whole scale presents $91 \%$ specificity and $86 \%$ sensitivity (Varo et al., 2006). The cut-off point for the anxiety subscale is 4 or more points and 2 or more points for the depression subscale. Higher point values indicate a more severe problem with 9 as the highest possible value for each subscale.

Sociodemographic questionnaire. A brief survey was used to collect personal data, such as age, gender, quality of internet connection, personal computer (owned or shared), cost of online learning (expensive or cheap), number of people living in the household, and years of academic program completed. 


\subsection{Procedures}

The GADS survey has been adapted to Spanish using criteria of the Bulletin of the International Test Commission (Hambleton \& Bollwark, 1991; Hambleton \& Kanjee, 1995). The protocols of this study were in accordance with the APA's Ethical Principles of Psychologists and Code of Conduct for students who voluntarily and anonymously participate, and who are informed of the confidential nature of the data provided and of the possibility of withdrawing at any time. The students invited to take part were first- to fifth-year students who voluntarily agreed to respond to the questionnaire. Simultaneously, the instrument was sent, and they were instructed to return it via email at any time. Additionally, the questionnaires were completed individually and took approximately 7 minutes to complete. The data collection process was conducted during voluntary COVID-19 lockdown during the second university semester (October-November 2020) and before the final exams period, highlighting the anonymous character of the data obtained.

\subsection{Data Analysis}

The capture and processing of data was done with the Microsoft Office Software and exported to Excel. Comparative analyses were also conducted to establish differences between the scores for anxiety and depression according to gender, for which the ROC curve and Mann-Whitney $U$ test of independent samples was used. These analyses were carried out using the Software Minitab 18 and the confidence interval applied in all the analyses was 95\% (Hoo et al., 2017; Kamarudin et al., 2017).

\section{Results}

\subsection{Anxiety and Depression in College Students from the BUAP-México}

The college student groups identified by GADS scale are shown in Table 1. In men, the prevalence of anxiety and depression were $75.5 \%$ and $63.5 \%$ respectively,

Table 1. Student groups identified with GADS.

\begin{tabular}{ccccc}
\hline & \multicolumn{2}{c}{ Men $(\mathbf{n}=192)$} & \multicolumn{2}{c}{ Women $(\mathbf{n}=310)$} \\
\cline { 2 - 5 } & Anxiety (\%/n) & Depression (\%/n) & Anxiety (\%/n) & Depression (\%/n) \\
TP & $75.5 / 145$ & $63.5 / 122$ & $92.3 / 286^{*}$ & $78.4 / 243^{*}$ \\
FP & $3.1 / 6$ & $6.3 / 12$ & $0.3 / 1$ & $3.6 / 11$ \\
TN & $17.7 / 34$ & $27.1 / 52$ & $5.8 / 18$ & $15.1 / 47$ \\
FN & $3.7 / 7$ & $3.1 / 6$ & $1.6 / 5$ & $2.9 / 9$ \\
Sensitivity & 0.9539 & 0.9531 & 0.9828 & 0.9643 \\
Specificity & 0.8500 & 0.8125 & 0.9474 & 0.8103 \\
\hline
\end{tabular}

TP, True Positive; FP, False Positive; TN, True Negative; FN, False Negative. ${ }^{*} \mathrm{p}<0.05$. U-Mann-Whitney, men vs women. 
while in women, the prevalence of anxiety and depression were significantly higher, $92.3 \%$ and $78.4 \%(\mathrm{p}<0.05)$ respectively in comparison to men. In all cases the sensitivity and specificity were superior to 0.80 and the ROC curves are shown in Figure 1.

In the current study also was obtained others data, such as age, gender, quality of internet connection, personal computer (owned or shared), cost of online learning (expensive or cheap), number of people living in the household (Table 2). Also, the years of academic program completed was obtained, in the latter case, there were no significant differences among college programs.

\subsection{Internet Connection Quality}

For men and women, internet connection disposition was $96.4 \%$ and $93.9 \%$ respectively, whereas no internet connection disposition was $3.6 \%$ and $6.1 \%$ respectively. In women, no internet connection was positively related to anxiety and depression and was increased significantly in comparison to men (Table 2). Furthermore, in women versus men, the depression increased significantly in the group that had no internet connection (Table 2). However, in men, anxiety increased significantly in the group with no internet connection, while in women, depression increased significantly in comparison to men (Table 2).

\subsection{Own PC or Share PC}

The proportion of men and women that owned a PC were $86.5 \%$ and $81 \%$ ( $\mathrm{p}<$ $0.05)$, and those who shared a PC were $13.5 \%$ and $19 \%(\mathrm{p}<0.05)$ respectively. In women, anxiety and depression increased significantly in comparison to men (92.8 vs 73.5 and 77.7 vs 60.8 , respectively). Also, in men, the anxiety and depression increased significantly in those that did not own a PC, whereas, in women only depression increased significantly when they shared a PC (Table 2).

\subsection{Cost of the Online Learning}

Men and women estimated the cost of online learning as expensive 28.6 and 31.9 , and cheap $71.4 \%$ and $68.1 \%$ respectively, with no statistically significant
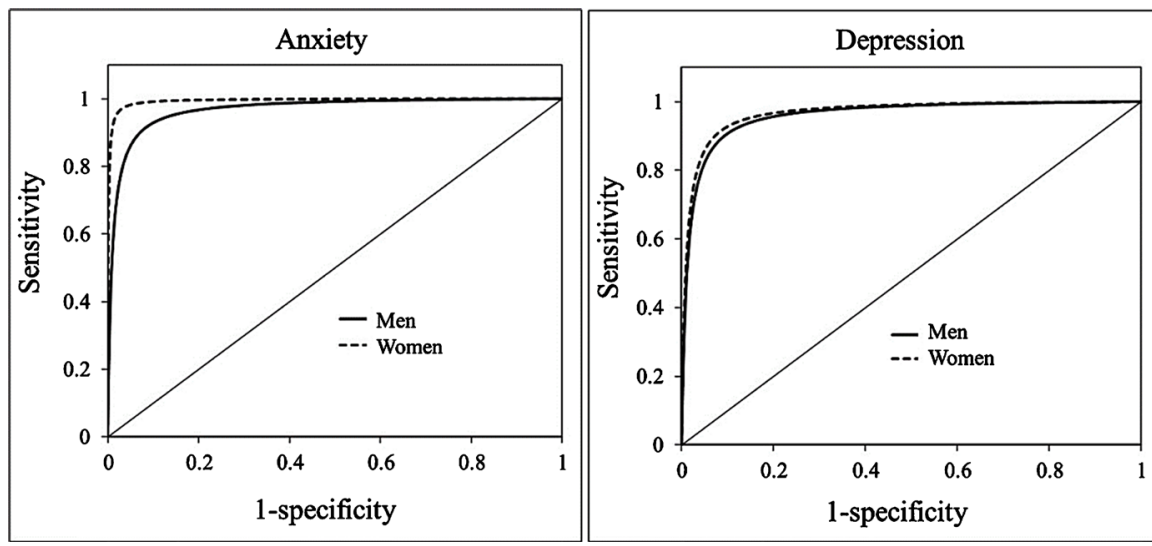

Figure 1. ROC curves. 
Table 2. Descriptive characteristics and association with anxiety and depression in college students of BUAP-México at COVID-19 lockdown.

\begin{tabular}{|c|c|c|c|c|c|c|c|}
\hline & \multirow[b]{2}{*}{ Subgroup } & \multicolumn{3}{|c|}{ Men $(n=192)$} & \multicolumn{3}{|c|}{ Women $(n=310)$} \\
\hline & & $\mathbf{n}$ & $\begin{array}{c}\text { Anxiety } \\
\% / n\end{array}$ & $\begin{array}{c}\text { Depression } \\
\% / \mathrm{n}\end{array}$ & $\mathrm{n}$ & $\begin{array}{c}\text { Anxiety } \\
\% / n\end{array}$ & $\begin{array}{c}\text { Depression } \\
\% / \mathrm{n}\end{array}$ \\
\hline Total & & 192 & $75.5 / 145$ & $63.5 / 122$ & 310 & $92.3 / 286^{*}$ & $78.4 / 243^{*}$ \\
\hline \multirow{2}{*}{ Internet } & Yes & 185 & $75.1 / 139$ & $63.8 / 118^{\#}$ & 291 & $92.4 / 269^{*}$ & $78.7 / 229^{*}$ \\
\hline & Not & 7 & $85.7 / 6^{\#}$ & $57.1 / 4$ & 19 & $89.5 / 17$ & $73.7 / 14^{*}$ \\
\hline \multirow{2}{*}{ Own PC } & Yes & 166 & $73.5 / 122$ & $60.8 / 101$ & 251 & $92.8 / 233^{*}$ & $77.7 / 195^{\star}$ \\
\hline & Not & 26 & $88.5 / 23^{\#}$ & $80.8 / 21^{\#}$ & 59 & $89.8 / 53$ & $81.3 / 48$ \\
\hline \multirow{2}{*}{ Share PC } & Yes & 78 & $84.5 / 66^{\#}$ & $69.2 / 54^{\#}$ & 155 & $93.5 / 145^{\star}$ & $81.3 / 126^{* \#}$ \\
\hline & Not & 106 & $67.9 / 72$ & $54.5 / 62$ & 143 & $91.6 / 131^{\star}$ & $74.8 / 107^{\star}$ \\
\hline \multirow{2}{*}{ Cost } & Expensive & 55 & $87.3 / 48^{\star *}$ & $69.1 / 38^{* \#}$ & 99 & $52.5 / 52$ & $50.5 / 50^{*}$ \\
\hline & Cheap & 137 & $70.8 / 97^{*}$ & $61.3 / 84^{*}$ & 211 & $58.3 / 123^{\#}$ & $44.5 / 94$ \\
\hline \multirow{5}{*}{$\begin{array}{l}\text { Years in } \\
\text { academic } \\
\text { program }\end{array}$} & 1 & 53 & $83 / 44$ & $64.1 / 34$ & 88 & $96.6 / 85^{*}$ & $82.9 / 73^{*}$ \\
\hline & 2 & 35 & $80 / 28$ & $68.6 / 24$ & 57 & $93 / 53^{*}$ & $82.4 / 47^{\star}$ \\
\hline & 3 & 28 & $78.6 / 22$ & $57.1 / 16$ & 47 & $89.4 / 42^{*}$ & $76.6 / 36^{*}$ \\
\hline & 4 & 60 & $71.7 / 43$ & $68.3 / 41$ & 79 & $88.6 / 70^{*}$ & $74.7 / 59^{*}$ \\
\hline & 5 or + & 16 & $50 / 8$ & $43.7 / 7$ & 39 & $92.3 / 36^{*}$ & $71.8 / 28^{\star}$ \\
\hline \multirow{5}{*}{$\begin{array}{c}\text { Inhabitants } \\
\text { per house }\end{array}$} & 1 & 3 & $33.3 / 1$ & $33.3 / 1$ & 4 & $100 / 4^{*}$ & $50 / 2^{*}$ \\
\hline & 2 & 9 & $77.8 / 7$ & $66.7 / 6$ & 13 & $92.3 / 12^{\star}$ & $84.6 / 11^{\star}$ \\
\hline & 3 & 35 & $68.6 / 24$ & $60 / 21$ & 41 & $92.7 / 38^{*}$ & $80.5 / 33^{*}$ \\
\hline & 4 & 67 & $82.1 / 55$ & $67.2 / 45$ & 91 & $90.1 / 82^{*}$ & $73.6 / 67^{\star}$ \\
\hline & 5 or + & 78 & $74.3 / 58$ & $62.8 / 49$ & 161 & $93.7 / 150^{*}$ & $80.7 / 130^{*}$ \\
\hline
\end{tabular}

${ }^{*} \mathrm{p}<0.05$ Mann-Whitney U test, men vs women. ${ }^{\sharp} \mathrm{p}<0.05$ Mann-Whitney U test, yes vs not.

differences between them. In men vs women, anxiety and depression were significantly higher when the cost was expensive (Table 2).

\subsection{Year in Academic Program}

In the group studied, we had men and women $27.6 \%, 18.2 \%, 14.6 \%, 31.3 \%, 8.3 \%$ and $28.4 \%, 18.4 \%, 15.2 \%, 25.5 \%, 12.5 \%$ at $1-5$ or more years in the academic program. For all academic years, in women, levels of anxiety and depression were significantly higher in comparison to men (Table 2).

\subsection{Inhabitants per House}

For the men and women student group, inhabitants per house were $1.6 \%, 4.7 \%$, $18.2 \%, 34.9 \%, 40.6 \%$ and $1.3 \%, 4.2 \%, 13.2 \%, 29.4 \%, 51.9 \%, 1-5$ or more people respectively. In all subgroups, among women, anxiety and depression were significantly higher in comparison to men (Table 2). While in men, anxiety and depression frequency were lowest, less than $34 \%$ (Table 2). 


\subsection{Clinical Symptoms Associated to Anxiety and Depression}

In both men and women students there was a high frequency of all clinical symptoms associated to anxiety; excitability, nervousness and tension, concern, irritability, difficulty relaxing and sleeping, headache, health concerns and difficulty falling asleep, however these clinical symptoms were significantly higher in women vs men (Table 2) (Figure 2). Likewise, clinical symptoms associated with depression; low energy, lost interest in things they used to enjoy, loss of self-confidence, hopelessness, difficulty concentrating, and waking up too early were above $50 \%$ in frequency in both men and women. Whereas, weight loss and waking up too early were less than $20 \%$ in frequency in both studied groups (Figure 3).

\section{Discussion}

The outburst of COVID-19 upended public life in society in all countries around the world. One of the immediate changes was the closure of schools and universities to slow the spread of SARS-CoV-2. To continue academic instruction, alternative teaching methods for the online delivery of education were very quickly introduced and represented a challenge in learning. However, these measures can have long-term consequences on the lives of students (Cohen et al. 2020). When we collected the data (October-November 2020), the students included in

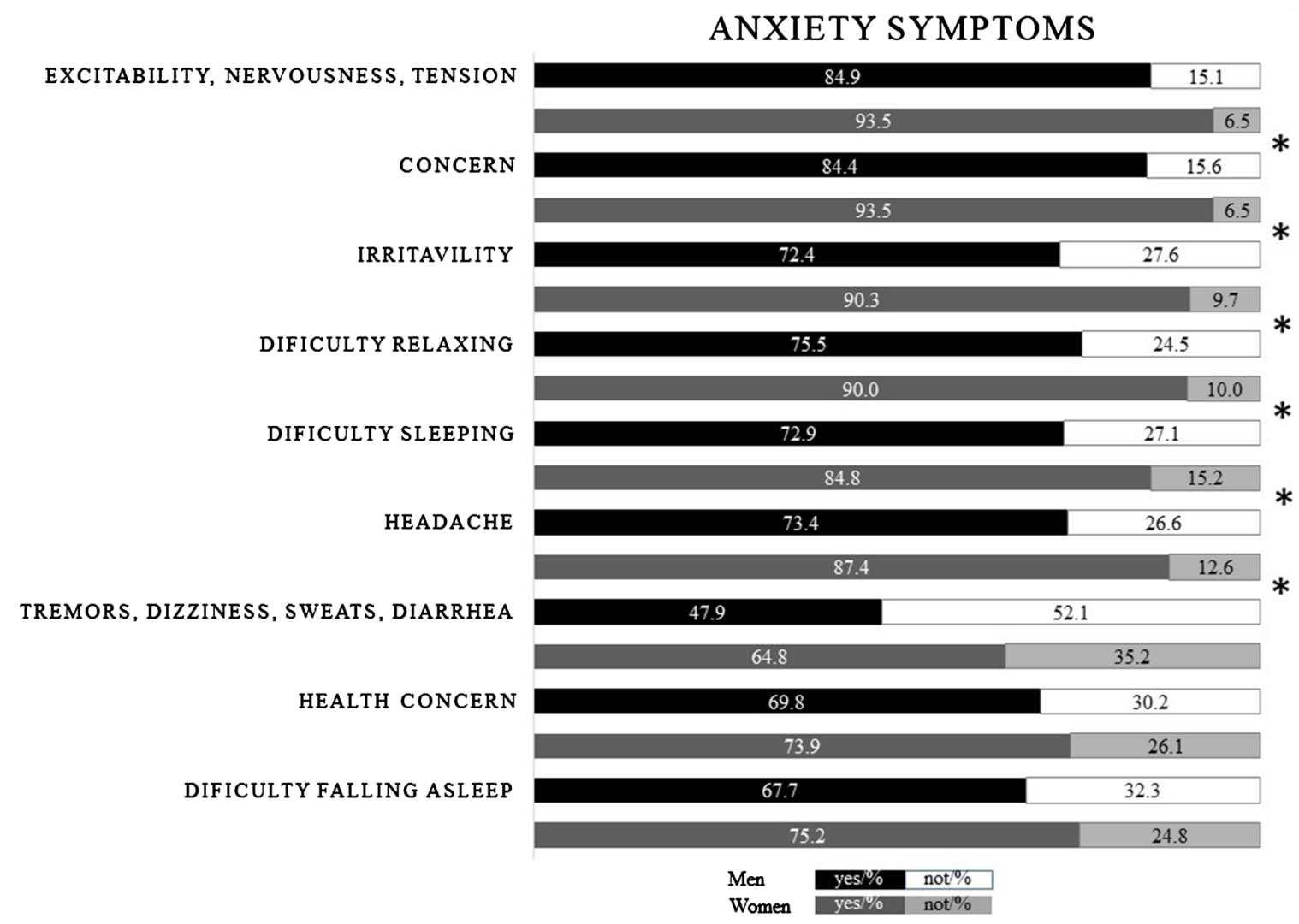

Figure 2. Clinical symptoms associated to anxiety in college students of BUAP-México at COVID-19 lockdown. GADS. ${ }^{\star} \mathrm{p}<0.05$, Mann-Whitney U test. 
DEPRESSION SYMPTOMS

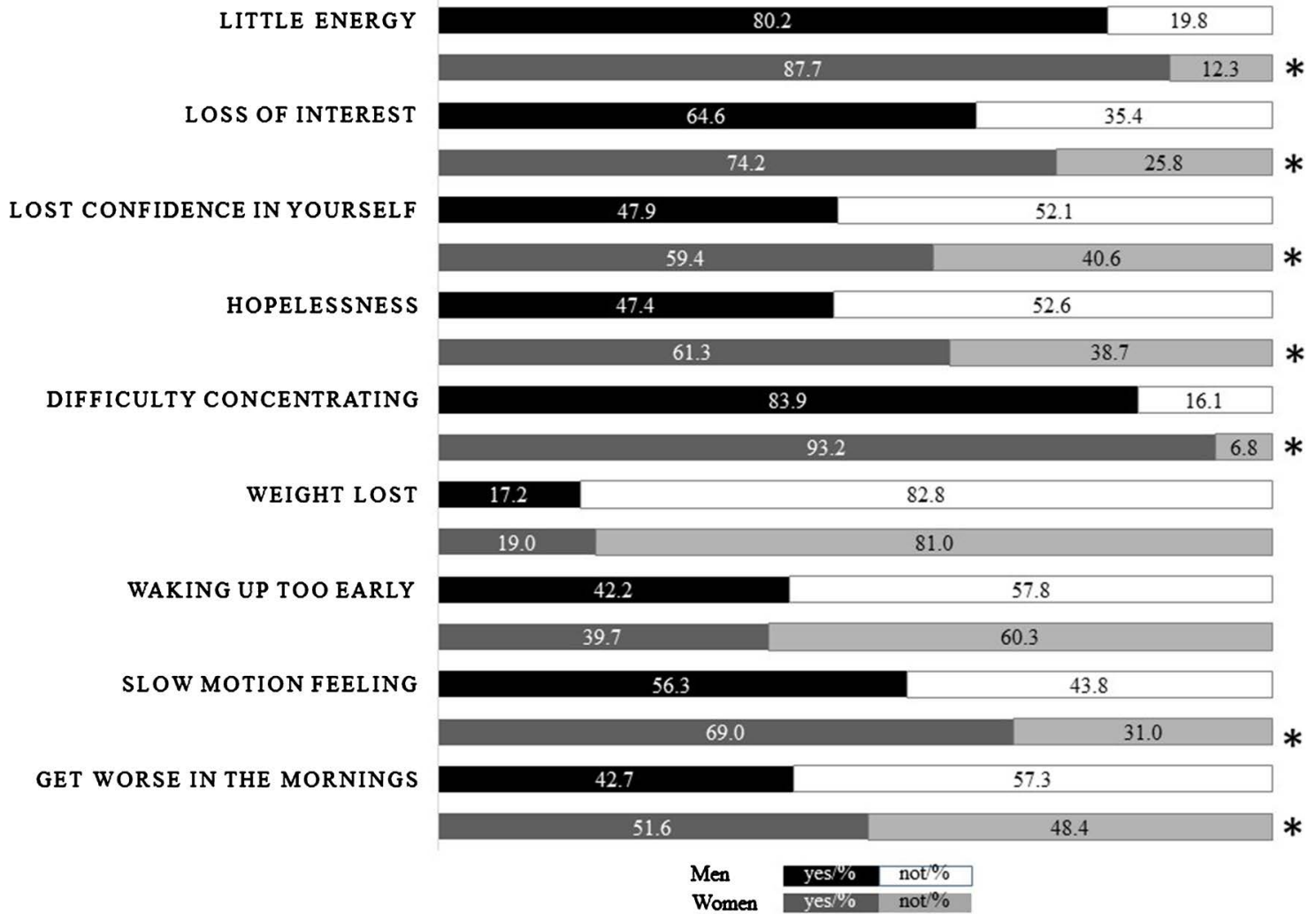

Figure 3. Clinical symptoms associated with depression in college students of BUAP-México at COVID-19 lockdown. GADS. ${ }^{*} \mathrm{p}<0.05$, Mann-Whitney U test.

this study had been in confinement for a very long time (seven months). Our results showed that anxiety and depression levels in both men and women college students were higher during COVID-19 lockdown (Table 1) in comparison to data reported deprived of COVID-19 (González-Benítez et al., 2020). These data are in line with others obtained in populations of college students in Greece (Kaparounaki et al., 2020), Lebanon (Fawaz \& Samaha, 2020), Bangladesh (Khan et al., 2020), China (Huang \& Zhao, 2020) and Switzerland (Elmer et al., 2020), among others. The prevalence of depressive symptoms is influenced by economic and sociocultural contexts (Fawaz \& Samaha, 2020; Islam et al., 2020; Kaparounaki et al., 2020); therefore, it needs to be evaluated in different circumstances. Long confinement is a condition primed for a greatly disturbing and stimulating crisis for public health in a population. Besides, the increasing mortality rate of COVID-19 in México had also been sadness from a spike of the painful psychological consequences in the population (Araújo et al., 2020; Czabanowska \& Kuhlmann, 2021; Kshirsagar et al., 2021). Furthermore, the closure of educational institutions, in the students, activates a sense of uncertainty relating to their academic careers and intensifies mental health challenges between college students (Chandratre, 2020; Jenei et al., 2020). There are many factors associated with the increased prevalence of anxiety disorder and depression caused by the COVID-19 lockdown, such as students participating in part-time 
jobs needed to provide funds for tuition and to support their families in the lock-in situation (Fawaz \& Samaha, 2020), isolation in social networks, lack of emotional interaction and support, and physical isolation, which were associated with negative mental health trajectories (Elmer et al., 2020).

In this study, the anxiety and depression increased in men and women students, $1.56-1.32$ and $1.42-1.44$ times respectively by COVID-19 lockdown in comparison to our previous published data collected in a cohort that did not experience the COVID-19 (González-Benítez et al., 2020). These results reveal an increase in anxiety and depression level linked with the COVID-19 lockdown. Also, there were gender differences with higher anxiety and depression levels in women than in men (Table 1). In other studies, published by other authors, female versus male students also scored significantly higher for anxiety and depression (Debowska et al., 2020). The signs of increased deterioration of mental health in women than in men has been associated with more worries about one's family and friends, more worries about the future career prospects, being faced with problems usually suppressed, living alone, and less contact and support from the personal network (Cohen et al., 2020; Owolabi, 2020). Likewise, higher anxiety and depression in college students has been associated with the age of the population. In this way, it had been informed that young adult students (18 24 years old) had more symptoms of depression, anxiety, and suicidality than adult students ( $\geq 25$ years old) (Debowska et al., 2020). However, some personality behaviors have been correlated with positive psychological outcomes. Individuals with positive coping styles, secure and avoidant attachment styles usually presented fewer symptoms of anxiety and stress (Wang et al., 2020). Also, it has been found that college students with more social support and time to rest during the pandemic exhibited lower stress levels (Zhang \& Ma, 2020).

Online learning environment. In Mexican college students, those who shared a PC, reported expensive costs, and had bad internet quality, showed increased anxiety and depression levels (Table 2). These work conditions at home have been previously related with low levels of student satisfaction with online learning and higher prevalence of depression, anxiety, and stress; low satisfaction was also found to be a phycological predictor of disease (Fawaz \& Samaha, 2020). Also, the number of residents per house increased the level of anxiety and depression in men and women. However, women were more affected than men (Table 2). These results are consistent with others where women students with anxiety disorder increased with COVID-19 lockdown (Reznik et al., 2020; Santini et al., 2020). Students living with families were 2.6 times more likely to be depressed than students living apart from families, and they were 1.8 times more severe anxiety symptoms than students staying away from families during the COVID-19 lockdown (Islam et al., 2020). Students have reported that they receive lots of emails every day, a lot of assignments and requirements to cover which makes day to day living with heavy workloads very stressful (Fernández-Castillo, 2021; Mheidly et al., 2020). During the times of COVID-19 lockdown there has 
been an emphasized higher need for psychological counseling of students due to the increased levels of stress and moral distress of the students as a result of the drastic change in the learning environment and the future prospects of their careers (Sundarasen et al., 2020). Therefore, new strategies need to be proposed to address these psychological factors and the psychological health of students. Synchronous online residency conferences have been associated with decreased engagement and attention by learners. It has been suggested that increasing interactivity may help improve the online classroom experience and cultivate novel teaching environments (Weber \& Ahn, 2020). Various studies have proved that low student satisfaction with the learning process has a significant relationship with the learning outcome; therefore the consequences of online learning might negatively affect the students' progress and academic achievement (Abbasi et al., 2020; Shahzad et al., 2020).

Years in an academic program. In the current study, both women and men recorded high anxiety and depression levels along the years in an academic program (Table 2). It is evident that COVID-19 lockdown affected all students, in all studying years, but that women had significant differences in anxiety and depression in comparison to men. These results are like others, where among final-year students, physical activity was significantly low. Students in higher years of study were more sedentary due to a higher workload. In the final year of their undergraduate studies they reported feeling more worried because they must pass final exams and get active on the job market (Romero-Blanco et al., 2020). In terms of grades, being a senior high school student was a risk factor for depressive and anxiety symptoms (Zhou et al., 2020). In addition, during COVID-19 lockdown, some behaviors changed among college students: including food ingestion, alcohol and smoking, increasing in the second, third and fourth years of study, in those living in a university residence, shared apartment, or with family (Romero-Blanco et al., 2020).

Anxiety and depression symptoms. Our data show that Mexican college students have suffered from great psychological impacts due to the COVID-19 lockdown. Women and men recorded high excitability, nervousness, tension, concern and irritability, difficulty relaxing, difficulty falling asleep, and headache. But the female students were significantly associated with higher scores than male students (Figure 2). These results are consistent with other studies realized at transition in e-learning during COVID-19 lockdown, where the most common reported anxiety symptoms were difficulty concentrating and feeling anxious or overwhelmed (Fitzgerald \& Konrad, 2021; Vigo et al., 2021) with the potential to sidetrack students in their academic studies. On depression symptoms, Mexican college students also recorded high frequency of little energy, lost confidence in themselves, hopelessness, difficulty concentrating, feelings of slow motion which were worse in the morning (Figure 3). The significant increase in depression symptoms has been highly correlated with worsened sleep quality, even insomnia (Evans et al., 2021; Marelli et al., 2020; Solomou \& Constantini- 
dou, 2020) with higher impact in students from lower socioeconomic level (Rudenstine et al., 2021). The COVID-19 lockdown and the transition to all online instruction had a negative impact on these students' ability to move forward in their academic program. It has been suggested that negative factors that increase anxiety and depression can be consistently decreased by the physical activities of students (Li et al., 2021). However, it is important to explore proactive and innovative policies, programs, and practices to promote student health and well-being.

\section{Limitations}

There are some limitations to our study that should be noted. A limitation is the sampling technique used. It relies on digital infrastructure and voluntary participation that increases selection bias. Another limitation of this study is the cross-sectional nature of the survey; as the pandemic changes, the mental health of university students may also change. Additionally, the researchers were unable to access more students from other specialties such as health, social and legal sciences, engineering, and architecture, which might have given a richer perspective into the research question.

\section{Conclusion}

Our results indicated that the COVID-19 lockdown had a significant impact on mental health among exact and natural sciences college students of the BUAP-México, which affected women more than men. The factors influencing at-home learning such as internet connection quality, internet cost, the status of owning or sharing a PC, inhabitants per household, and length of academic program completed were positively correlated to higher anxiety and depression registered by the students that participated in this project. The findings of this study highlight the urgent need to develop interventions, relaxation psychological activities and protective strategies to address the mental health of college students to facilitate a better quality of education.

\section{Acknowledgements}

Alan Carrasco-Carballo and Alberto Rojas-Morales were supported by CONACYT/ 698207,834462 through the doctoral and master programs respectively.

\section{Conflicts of Interest}

The authors declare no conflicts of interest regarding the publication of this paper.

\section{References}

Abbasi, M. S., Ahmed, N., Sajjad, B., Alshahrani, A., Saeed, S., Sarfaraz, S., Alhamdan, R. S., Vohra, F., \& Abduljabbar, T. (2020). E-Learning Perception and Satisfaction among Health Sciences Students amid the COVID-19 Pandemic. Work, 67, 549-556. 
https://doi.org/10.3233/WOR-203308

Almaiah, M. A., Al-Khasawneh, A., \& Althunibat, A. (2020). Exploring the Critical Challenges and Factors Influencing the E-Learning System Usage during COVID-19 Pandemic. Education and Information Technologies, 25, 5261-5280. https://doi.org/10.1007/s10639-020-10219-y

Araújo, F. J. O., de Lima, L. S. A., Cidade, P. I. M., Nobre, C. B., \& Neto, M. L. R. (2020). Impact of SARS-CoV-2 and Its Reverberation in Global Higher Education and Mental Health. Psychiatry Research, 288, Article ID: 112977. https://doi.org/10.1016/j.psychres.2020.112977

Chandratre, S. (2020). Medical Students and COVID-19: Challenges and Supportive Strategies. Journal of Medical Education and Curricular Development, 7. https://doi.org/10.1177/2382120520935059

Cohen, A. K., Hoyt, L. T., \& Dull, B. (2020). A Descriptive Study of Coronavirus Disease 2019-Related Experiences and Perspectives of a National Sample of College Students in Spring 2020. Journal of Adolescent Health, 67, 369-375.

Cortés-Álvarez, N. Y., Piñeiro-Lamas, R., \& Vuelvas-Olmos, C. R. (2020). Psychological Effects and Associated Factors of COVID-19 in a Mexican Sample. Disaster Medicine and Public Health Preparedness, 14, 413-424. https://doi.org/10.1017/dmp.2020.215

Czabanowska, K., \& Kuhlmann, E. (2021). Public Health Competences through the Lens of the COVID-19 Pandemic: What Matters for Health Workforce Preparedness for Global Health Emergencies. The International Journal of Health Planning and Management, 36, 14-19. https://doi.org/10.1002/hpm.3131

Debowska, A., Horeczy, B., Boduszek, D., \& Dolinski, D. (2020). A Repeated Cross-Sectional Survey Assessing University Students' Stress, Depression, Anxiety, and Suicidality in the Early Stages of the COVID-19 Pandemic in Poland. Psychological Medicine, 1-4. https://doi.org/10.1017/S003329172000392X

Elmer, T., Mepham, K., \& Stadtfeld, C. (2020). Students under Lockdown: Comparisons of Students' Social Networks and Mental Health before and during the COVID-19 Crisis in Switzerland. PLOS ONE, 15, e0236337.

https://doi.org/10.1371/journal.pone.0236337

Evans, S., Alkan, E., Bhangoo, J. K., Tenenbaum, H., \& Ng-Knight, T. (2021). Effects of the COVID-19 Lockdown on Mental Health, Wellbeing, Sleep, and Alcohol Use in a UK Student Sample. Psychiatry Research, 298, Article ID: 113819. https://doi.org/10.1016/j.psychres.2021.113819

Fawaz, M., \& Samaha, A. (2020). E-Learning: Depression, Anxiety, and Stress Symptomatology among Lebanese University Students during COVID-19 Quarantine. Nursing Forum, 56, 52-57. https://doi.org/10.1111/nuf.12521

Fernández-Castillo, A. (2021). State-Anxiety and Academic Burnout Regarding University Access Selective Examinations in Spain during and after the COVID-19 Lockdown. Frontiers in Psychology, 12, Article ID: 621863. https://doi.org/10.3389/fpsyg.2021.621863

Fiorillo, A., \& Gorwood, P. (2020). The Consequences of the COVID-19 Pandemic on Mental Health and Implications for Clinical Practice. European Psychiatry, 63, e32. https://doi.org/10.1192/j.eurpsy.2020.35

Fitzgerald, A., \& Konrad, S. (2021). Transition in Learning during COVID-19: Student Nurse Anxiety, Stress, and Resource Support. Nursing Forum, 56, 298-304. https://doi.org/10.1111/nuf.12547

Goldberg, D., Bridges, K., Duncan-Jones, P., \& Grayson, D. (1988). Detecting Anxiety 
and Depression in General Medical Settings. BMJ (Clinical Research Ed.), 297, 897-899. https://doi.org/10.1136/bmj.297.6653.897

González-Benítez, A. G., Luna-Centeno, L. D., Alatriste, V., Carrasco-Carballo, A., Martínez, I., Martínez, L., Limón, D., \& Luna, F. (2020). Ansiedad y Depresión en los Estudiantes de Licenciatura de Ciencias Naturales y Exactas de la BUAP-México. Alianzas y Tendencias BUAP, 5, 41-55. https://eoi.citefactor.org/10.11235/BUAP.05.19.03

González-Ramírez, L. P., Martínez, Arriaga, R. J., Hernández-González, M. A., \& De la Roca-Chiapas, J. M. (2020). Psychological Distress and Signs of Post-Traumatic Stress in Response to the COVID-19 Health Emergency in a Mexican Sample. Psychology Research and Behavior Management, 13, 589-597. https://doi.org/10.2147/PRBM.S259563

Hambleton, R. K., \& Bollwark, J. (1991). Adapting Tests for Use in Different Cultures: Technical Issues and Methods. https://eric.ed.gov/?id=ED337481

Hambleton, R. K., \& Kanjee, A. (1995). Increasing the Validity of Cross-Cultural Assessments: Use of Improved Methods for Test Adaptations. European Journal of Psychological Assessment, 11, 147-157. https://doi.org/10.1027/1015-5759.11.3.147

Hoo, Z. H., Candlish, J., \& Teare, D. (2017). What is a ROC Curve? Emergency Medicine Journal, 34, 357-359. https://doi.org/10.1136/emermed-2017-206735

Huang, Y., \& Zhao, N. (2020). Generalized Anxiety Disorder, Depressive Symptoms and Sleep Quality during COVID-19 Outbreak in China: A Web Based Cross-Sectional Survey. Psychiatry Research, 288, Article ID: 112954.

https://doi.org/10.1016/j.psychres.2020.112954

Islam, M. A., Barna, S. D., Raihan, H., Khan, M. N. A., \& Hossain, M. T. (2020). Depression and Anxiety among University Students during the COVID-19 Pandemic in Bangladesh: A Web-Based Cross-Sectional Survey. PLoS ONE, 15, e0238162. https://doi.org/10.1371/journal.pone.0238162

Jenei, K., Cassidy-Matthews, C., Virk, P., Lulie, B., \& Closson, K. (2020). Challenges and Opportunities for Graduate Students in Public Health during the COVID-19 Pandemic. Canadian Journal of Public Health, 111, 408-409. https://doi.org/10.17269/s41997-020-00349-8

Kamarudin, A. N., Cox, T., \& Kolamunnage-Dona, R. (2017). Time-Dependent ROC Curve Analysis in Medical Research: Current Methods and Applications. BMC Medical Research Methodology, 17, 53. https://doi.org/10.1186/s12874-017-0332-6

Kang, L., Li, Y., Hu, S., Chen, M., Yang, C., Yang, B. X., Wang, Y., Hu, J., Lai, J., Ma, X., Chen, J., Guan, L., Wang, G., Ma, H., \& Liu, Z. (2020). The Mental Health of Medical Workers in Wuhan. China Dealing with the 2019 Novel Coronavirus 7. The Lancet Psychiatry, 7, e14. https://doi.org/10.1016/S2215-0366(20)30047-X

Kaparounaki, C. K., Patsali, M. E., Mousa, D. V., Papadopoulou, E. V. K., Papadopoulou, K. K. K., \& Fountoulakis, K. N. (2020). University Students' Mental Health amidst the COVID-19 Quarantine in Greece. Psychiatry Research, 290, Article ID: 113111. https://doi.org/10.1016/j.psychres.2020.113111

Khan, A. H., Sultana, M. S., Hossain, S., Hasan, M. T., Ahmed, H. U., \& Sikder, M. T. (2020). The Impact of COVID-19 Pandemic on Mental Health \& Wellbeing among Home-Quarantined Bangladeshi Students: A Cross-Sectional Pilot Study. Journal of Affective Disorders, 277, 121-128. https://pubmed.ncbi.nlm.nih.gov/32799105 https://doi.org/10.1016/j.jad.2020.07.135

Kshirsagar, M. M., Dodamani, A. S., Dodamani, G. A., Khobragade, V. R., \& Deokar, R. N. (2021). Impact of COVID-19 on Mental Health: An Overview. Reviews on Recent Clinical Trials. https://doi.org/10.2174/1574887115666210105122324 
Li, H., Hafeez, H., \& Zaheer, M. A. (2021). COVID-19 and Pretentious Psychological Well-Being of Students: A Threat to Educational Sustainability. Frontiers in Psychology, 11, Article ID: 628003. https://doi.org/10.3389/fpsyg.2020.628003

Marelli, S., Castelnuovo, A., Somma, A., Castronovo, V., Mombelli, S., Bottoni, D., Leitner, C., Fossati, A., \& Ferini-Strambi, L. (2020). Impact of COVID-19 Lockdown on Sleep Quality in University Students and Administration Staff. Journal of Neurology, 268, 8-15. https://doi.org/10.1007/s00415-020-10056-6

Mazza, C., Ricci, E., Biondi, S., Colasanti, M., Ferracuti, S., Napoli, C., \& Roma, P. (2020). A Nationwide Survey of Psychological Distress among Italian People during the COVID-19 Pandemic: Immediate Psychological Responses and Associated Factors. International Journal of Environmental Research and Public Health, 17, 3165. https://doi.org/10.3390/ijerph17093165

Mheidly, N., Fares, M. Y., \& Fares, J. (2020). Coping with Stress and Burnout Associated with Telecommunication and Online Learning. Frontiers in Public Health, 8, Article ID: 574969 . https://doi.org/10.3389/fpubh.2020.574969

Nimavat, N., Singh, S., Fichadiya, N., Sharma, P., Patel, N., Kumar, M., Chauhan, G., \& Pandit, N. (2021). Online Medical Education in India-Different Challenges and Probable Solutions in the Age of COVID-19. Advances in Medical Education and Practice, 12, 237-243. https://doi.org/10.2147/AMEP.S295728

Odriozola-González, P., Planchuelo-Gómez, Á., Irurtia, M. J., \& de Luis-García, R. (2020). Psychological Effects of the COVID-19 Outbreak and Lockdown among Students and Workers of a Spanish University. Psychiatry Research, 290, Article ID: 113108. https://doi.org/10.1016/j.psychres.2020.113108

Owolabi, J. O. (2020). Virtualising the School during COVID-19 and beyond in Africa: Infrastructure, Pedagogy, Resources, Assessment, Quality Assurance, Student Support System, Technology, Culture and Best Practices. Advances in Medical Education and Practice, 11, 755-759. https://doi.org/10.2147/AMEP.S272205

Padrón, I., Fraga, I., Vieitez, L., Montes, C., \& Romero, E. (2021). A Study on the Psychological Wound of COVID-19 in University Students. Frontiers in Psychology, 12, Article ID: 589927. https://doi.org/10.3389/fpsyg.2021.589927

Pappa, S., Ntella, V., Giannakas, T., Giannakoulis, V. G., Papoutsi, E., \& Katsaounou, P. (2020). Prevalence of Depression, Anxiety, and Insomnia among Healthcare Workers during the COVID-19 Pandemic: A Systematic Review and Meta-Analysis. Brain, Behavior, and Immunity, 88, 901-907. https://doi.org/10.1016/j.bbi.2020.05.026

Ramos-Morcillo, A. J., César, Leal-Costa, C., Moral-García, J. E., \& Ruzafa-Martínez, M. (2020). Experiences of Nursing Students during the Abrupt Change from Face-to-Face to E-Learning Education during the First Month of Confinement Due to COVID-19 in Spain. International Journal of Environmental Research and Public Health, 17, 5519.

https://www.mdpi.com/1660-4601/17/15/5519

https://doi.org/10.3390/ijerph17155519

Rehman, U., Shahnawaz, M. G., Khan, N. H., Kharshiing, K. D., Khursheed, M., Gupta, K., Kashyap, D., \& Uniyal, R. (2020). Depression, Anxiety and Stress among Indians in Times of COVID-19 Lockdown. Community Mental Health Journal, 57, 42-48.

https://link.springer.com/article/10.1007/s10597-020-00664-x https://doi.org/10.1007/s10597-020-00664-x

Reznik, A., Gritsenko, V., Konstantinov, V., Khamenka, N., \& Isralowitz, R. (2020). COVID-19 Fear in Eastern Europe: Validation of the Fear of COVID-19 Scale. International Journal of Mental Health and Addiction, 1-6.

https://doi.org/10.1007/s11469-020-00283-3 
Rodríguez-Hidalgo, A. J., Pantaleón, Y., Dios, I., \& Falla, D. (2020). Fear of COVID-19, Stress, and Anxiety in University Undergraduate Students: A Predictive Model for Depression. Frontiers in Psychology, 11, Article ID: 591797.

https://doi.org/10.3389/fpsyg.2020.591797

Romero-Blanco, C., Rodríguez-Almagro, J., Onieva-Zafra, M. D., Parra-Fernández, M. L., Prado-Laguna, M. D. C., \& Hernández-Martínez, A. (2020). Physical Activity and Sedentary Lifestyle in University Students: Changes during Confinement Due to the COVID-19 Pandemic. International Journal of Environmental Research and Public Health, 17, 6567. https://doi.org/10.3390/ijerph17186567

Rudenstine, S., McNeal, K., Schulder, T., Ettman, C. K., Hernandez, M., Gvozdieva, K., \& Galea, S. (2021). Depression and Anxiety during the COVID-19 Pandemic in an Urban, Low-Income Public University Sample. Journal of Traumatic Stress, 34, 12-22. https://doi.org/10.1002/jts.22600

Sandín, B., Valiente, R. M., García-Escalera, J., \& Chorot, P. (2020). Impacto Psicológico de la Pandemia de COVID-19: Efectos Negativos y Positivos en Población Española Asociados al Periodo de Confinamiento Nacional. Journal of Psychopathology and Clinical Psychology, 25, 1-22. https://doi.org/10.5944/rppc.27569

Santini, Z. I., Jose, P. E., Cornwell, E. Y., Koyanagi, A., Nielsen, L., Hinrichsen, C., Meilstrup C., Madsen, K. R., \& Koushede, V. (2020). Social Disconnectedness, Perceived Isolation, and Symptoms of Depression and Anxiety among Older Americans (NSHAP): A Longitudinal Mediation Analysis. Lancet Public Health, 5, e62-e70.

https://pubmed.ncbi.nlm.nih.gov/31910981 https://doi.org/10.1016/S2468-2667(19)30230-0

SECGOB ACUERDO-a (2020). Por el que se Declara Como Emergencia Sanitaria por Causa de Fuerza Mayor, a la Epidemia de Enfermedad Generada por el Virus SARSCoV2 (COVID-19). DOF México, March 30, 2020 http://dof.gob.mx/nota_detalle.php?codigo $=5590745 \&$ fecha $=30 / 03 / 2020$

SECGOB ACUERDO-b (2020). Por el que se Establecen Acciones Extraordinarias Para Atender la Emergencia Sanitaria Generada por el Virus SARS-CoV2. DOF México, March 31, 2020.

https://dof.gob.mx/nota_detalle.php?codigo $=5590914 \&$ fecha $=31 / 03 / 2020$

Shah, S. M. A., Mohammad, D., Qureshi, M. F. H., Abbas, M. Z., \& Aleem, S. (2021). Prevalence, Psychological Responses and Associated Correlates of Depression, Anxiety and Stress in a Global Population, during the Coronavirus Disease (COVID-19) Pandemic. Community Mental Health Journal, 57, 101-110. https://doi.org/10.1007/s10597-020-00728-y

Shahzad, A., Hassan, R., Aremu, A. Y., Hussain, A., \& Lodhi, R. N. (2020). Effects of COVID-19 in E-Learning on Higher Education Institution Students: The Group Comparison between Male and Female. Quality \& Quantity, 1-22. https://doi.org/10.1007/s11135-020-01028-Z

Solomou, I., \& Constantinidou, F. (2020). Prevalence and Predictors of Anxiety and Depression Symptoms during the COVID-19 Pandemic and Compliance with Precautionary Measures: Age and Sex Matter. International Journal of Environmental Research and Public Health, 17, 4924. https://doi.org/10.3390/ijerph17144924

Sundarasen, S., Chinna, K., Kamaludin, K., Nurunnabi, M., Baloch, G. M., Khoshaim, H. B., Hossain, S. F. A., \& Sukayt, A. (2020). Psychological Impact of COVID-19 and Lockdown among University Students in Malaysia: Implications and Policy Recommendations. International Journal of Environmental Research and Public Health, 17, 6206. https://doi.org/10.3390/ijerph17176206 
Varo, M. B., Fernández, M. O., Cobos, F. M., Gutiérrez, P. V., \& Aragón, R. B. (2006). Intervención Grupal en los Trastornos de Ansiedad en Atención Primaria: Técnicas de Relajación y Cognitivo-Conductuales. SEMERGEN-Medicina de Familia, 32, 205-210. https://doi.org/10.1016/S1138-3593(06)73258-0

Vigo, D., Jones, L., Munthali, R., Pei, J., Westenberg, J., Munro, L., Judkowicz, C., Wang, A. Y., Van den Adel, B., Dulai, J., Krausz, M., Auerbach, R. P., Bruffaerts, R., Yatham, L., Gadermann, A., Rush, B., Xie, H., Pendakur, K., \& Richardson, C. (2021). Investigating the Effect of COVID-19 Dissemination on Symptoms of Anxiety and Depression among University Students. BJPsych Open, 7, e69.

https://doi.org/10.1192/bjo.2021.24

Wang, Y., Di, Y., Ye, J., \& Wei, W. (2020). Study on the Public Psychological States and Its Related Factors During the Outbreak of Coronavirus Disease 2019 (COVID-19) in Some Regions of China. Psychology, Health \& Medicine, 26, 13-26. https://doi.org/10.1080/13548506.2020.1746817

Weber, W., \& Ahn, J. (2020). COVID-19 Conferences: Resident Perceptions of Online Synchronous Learning Environments. The Western Journal of Emergency Medicine, 22, 115-118. https://doi.org/10.5811/westjem.2020.11.49125

Xiong, J., Lipsiz, O., Nasri, F., Lui, L. M. W., Gill, H., Phan, L., Chen-Li, D., Iacobucci, M., Ho, R., Majeed, A., \& McIntyre, R. S. (2020). Impact of COVID-19 Pandemic on Mental Health in the General Population: A Systematic Review. Journal of Affective Disorders, 277, 55-64. https://doi.org/10.1016/j.jad.2020.08.001

Zhai, Y., \& Du, X. (2020). Addressing Collegiate Mental Health amid COVID-19 Pandemic. Psychiatry Research, 288, Article ID: 113003. https://doi.org/10.1016/j.psychres.2020.113003

Zhang, Y., \& Ma, Z. F. (2020). Impact of the COVID-19 Pandemic on Mental Health and Quality of Life among Local Residents in Liaoning Province, China: A Cross-Sectional Study. International Journal of Environmental Research and Public Health, 17, Article No. 2381. https://doi.org/10.3390/ijerph17072381

Zhou, S. J., Zhang, L. G., Wang, L. L., Guo, Z. C., Wang, J. Q., Chen, J. C., Liu, M., Chen, X., \& Chen, J. X. (2020). Prevalence and Socio-Demographic Correlates of Psychological Health Problems in Chinese Adolescents during the Outbreak of COVID-19. European Child \& Adolescent Psychiatry, 29, 749-758.

https://doi.org/10.1007/s00787-020-01541-4 


\section{Appendix 1}

Questionnaire applied

All data will confident and not associated with any person. Annotate in space with an $\mathrm{x}$, the corresponding response

1. What is your gender? women ( ), man ( )

2. How old are you? ( ) years old

3. Do you have Internet connection in the house you live in?

Yes $\quad$ No

4. Do you have a computer for personal use?

5. Do you share your personal computer with the people you live with?

6. Have your online studies been more expensive than your face-to-face studies?

7. How many people live in the house you currently live in?

2

5 or more

8. What degree do you are studying?
a) Mathematics
b) Physics
c) Electronic
d) Computer
e) Chemistry
f) Biochemistry
g) Biology
h) Biotechnology
i) How many full years have you been advancing in the bachelor's degree program? 